\title{
Multi-output optimization of tribological characteristics control factors of thermally sprayed industrial ceramic coatings using hybrid Taguchi-grey relation analysis
}

\author{
Mohammed YUNUS*, Mohammad S. ALSOUFI \\ Mechanical Engineering Department, College of Engineering and Islamic Architecture, Umm Al-Qura University, Makkah 21514, Kingdom \\ of Saudi Arabia \\ Received: 02 April 2016 / Revised: 27 May 2016/ Accepted: 23 June 2016 \\ (C) The author(s) 2016. This article is published with open access at Springerlink.com
}

\begin{abstract}
Lasma-sprayed thermal barrier coatings (TBCs) are gaining wide popularity and becoming more attractive for many industrial applications due to their high strength, thermal barrier/fatigue characteristics at elevated temperatures, resistance to chemical degradation, wear resistance, and environmental corrosion protection provided when coated on the surface of engineering components. To characterize the tribological properties of TBCs, a better understanding of their failure mechanisms and a thorough investigation of their performance are required. In this research, we used Taguchi-based grey relational analysis (GRA) to optimize the process parameters of various tribological characteristics of ceramic coatings applied via an atmospheric plasma spray process. Using Taguchi L16 factorial mixed-level experimental design, we also evaluated tribological characteristics such as wear loss and the coefficient of friction. Using GRA, we successfully performed a multiple output optimization and ranking of the control factors. Based on ANOVA results, we evaluated the significance of each process parameter and validated our findings in tests using the obtained optimum set of process parameters. Our study results will help to minimize wear loss and the coefficient of friction and to maximize TBC life.
\end{abstract}

Keywords: tribological characteristics; wear loss; coefficient of friction; hybrid Taguchi-grey relational analysis; analysis of variance (ANOVA); thermal barrier coatings (TBCs)

\section{Introduction}

Due to rapid technological advancements and increasing competition, cost saving and improving the efficiency of existing materials are necessary. Today, coating and surface modification methods are utilized so that existing materials can withstand extreme pressures, cyclic stresses, high temperatures, and excessive wear. To prepare engineering surfaces to withstand severe working conditions and to extend the lives of engineering materials, thermally sprayed industrial ceramic coatings are applied to metal substrates in the aerospace, automotives, gas turbines,

* Corresponding author: Mohammed YUNUS.

E-mail: yunus.mohammed@rediffmail.com and power generation industries [1-5]. Thermal barrier coatings (TBCs) generally consist of two layers: a metallic bond coat that protects the metal substrate from oxidation, corrosion and increases adhesion strength to the thermal insulating layer, and a thermalbarrier ceramic coating that protects the metal from high temperatures, excessive wear, and corrosion. TBCs have been successfully used for wear and friction control of machineries parts and turbine vanes [6]. Table 1 shows the thermal characteristics control factors and levels studies of industrial ceramic TBCs applications in excessive wear conditions $[7,8]$. Experimental results obtained using a Taguchi L16 orthogonal array experimental designs are shown in Table 2 . 
Table 1 Control factors and their levels for tribological characteristics of TBC.

\begin{tabular}{ccccccc}
\hline \multirow{2}{*}{ Process parameters } & Notation & Unit & \multicolumn{3}{c}{ Levels of parameters } \\
\cline { 4 - 7 } & & & Level 1 & Level 2 & Level 3 & 0.25 \\
\hline Applied pressure & $P$ & $\mathrm{MPa}$ & 0.05 & 0.15 & 6 & 0.3 \\
Sliding distance & $D$ & $\mathrm{~km}$ & 2 & 4 & 7.5 & 10 \\
Sliding velocity & $V$ & $\mathrm{~m} / \mathrm{s}$ & 2.5 & 5 & Level 4 \\
Type of coating & $C$ & - & Alumina (A) & Alumina titania (AT) & Partial stabilized zirconia (PSZ) & Super-Z \\
\hline
\end{tabular}

Table 2 Taguchi L16 orthogonal array for experimental layout.

\begin{tabular}{cllll||ccccc}
\hline Run No. & $P$ & $D$ & $V$ & $C$ & Run No. & $P$ & $D$ & $V$ & $C$ \\
\hline 1 & 1 & 1 & 1 & 1 & 9 & 3 & 1 & 3 & 4 \\
2 & 1 & 2 & 2 & 2 & 10 & 3 & 2 & 4 & 3 \\
3 & 1 & 3 & 3 & 3 & 11 & 3 & 3 & 1 & 2 \\
4 & 1 & 4 & 4 & 4 & 12 & 3 & 4 & 2 & 1 \\
5 & 2 & 1 & 2 & 3 & 13 & 4 & 1 & 4 & 2 \\
6 & 2 & 2 & 1 & 4 & 14 & 4 & 2 & 3 & 1 \\
7 & 2 & 3 & 4 & 1 & 15 & 4 & 3 & 2 & 4 \\
8 & 2 & 4 & 3 & 2 & 16 & 4 & 4 & 1 & 3 \\
\hline
\end{tabular}

\subsection{Grey relational analysis (GRA)}

Deng [9] proposed the grey relational analysis (GRA) technique for measuring the degree of relationship between sequences of experiments using grey relational grading, and used it to optimize control parameters having multiple-outputs (responses or objectives) [9]. GRA can also be used in processes with little or incomplete information. The steps involved in the GRA process, as shown in Fig. 1, are described below.

First, the data must be preprocessed since the orders of magnitude of the control factors differ, and they are normalized by transforming the experimental measured units into dimensionless factors in a range

\begin{tabular}{|c|}
\hline Identify multiple response characteristics and process factors to be evaluated \\
\hline Determine mumber of levels for each control parameters \\
\hline Select appropriate orthogonal array (OA) and assign process factors to OA \\
\hline Conduct experiments based on the arrangement of OA \\
\hline Normalize the experiment results of wear loss and coefficient of friction \\
\hline Evaluate grey relational grade by averaging grey relational coefficient \\
\hline Analyze the experimental results using the grey relational grade and ANOVA \\
\hline Select the optimal levels of tribological parameters of TSC \\
\hline
\end{tabular}

Fig. 1 Various steps involved in hybrid Taguchi based grey relation analysis. of $0-1[9,10]$. Also called grey relational generation, in this step, the original sequences are converted into a set of comparable sequences. In this study, we used Taguchi-based GRA to optimize the tribological characteristics of two TBC parameters wear loss (WL) and coefficient of friction (COF) to withstand excessive wear based on the quality characteristics of the original data. We represented the original reference sequence and the pre-processed data (comparability sequence) by $x_{i}^{*}(k)$ and $x_{i}^{0}(k), i=1,2, \ldots, m, k=1,2, \ldots ., n$, respectively, where $m$ and $n$ are the number of experiments and observations of data, respectively. Depending on the quality characteristics, three methods are available for normalizing the original sequence. If the original sequence data has a quality characteristic such as "the smaller-the-better" in the GRA or linear data processing, the results or responses are normalized using Eq. (1) in the experimental data plan [11].

$$
x_{i}^{*}(k)=\frac{\max x_{i}^{0}(k)-x_{i}^{0}(k)}{\max x_{i}^{0}(k)-\min x_{i}^{0}(k)}
$$

where $x_{i}^{*}(k)$ is the sequence after the data processing also called as the compatibility sequence, and $x_{i}^{0}(k)$ is the original sequence of the target value. For our 
present analysis, $m=16$ and $n=2$.

Next, we determine the deviation coefficient, which is the absolute value of the difference between the reference and compatibility sequence, i.e.,

$$
\Delta_{i}^{\mathrm{o}}(k)=x_{\mathrm{o}}^{*}(k)-x_{i}^{*}(k)
$$

where $\Delta_{i}^{o}(k)$ is the deviation coefficient, and $x_{\mathrm{o}}^{*}(k)$ is the reference or ideal sequence. We then determine the grey relational coefficient using Eq. (3)

$$
\gamma=\left(x_{0}^{*}(k) \times x_{i}^{*}(k)\right)=\frac{{ }^{*} \Delta_{\min }+\varsigma \cdot \Delta_{\max }}{\Delta_{i}^{o}(k)+\varsigma \cdot \Delta_{\max }}
$$

where $\left(x_{0}^{*}(k) \times x_{i}^{*}(k)\right)$ is the grey relational coefficient and the distinguishing coefficient is $0-1$. The grey relational grade $\gamma\left(x_{0}^{*} \cdot x_{i}^{*}\right)$ is the weighted sum of the $\zeta$ grey relational coefficients and represents the level of correlation between the reference and compatibility sequences. It can be calculated using Eq. (4).

$$
\gamma\left(x_{0}^{*} \cdot x_{i}^{*}\right)=\frac{1}{N} \gamma\left(x_{0}^{*}(k) \cdot \gamma\left(x_{i}^{*}(k)\right)\right)
$$

The grey relational grades are then sequenced in descending order. Higher value grey relational grades indicate a stronger relational degree between the reference and compatibility sequences. The highest value of grey relational grade indicates the optimal combination of control parameters for the desired responses.

\section{Experimental procedures}

Using optimum spray parameters, we prepared and coated standard specimens with four different commercially available industrial ceramic coating materials, including alumina $\left(\mathrm{Al}_{2} \mathrm{O}_{3}\right)$, alumina-titania $\left(\mathrm{Al}_{2} \mathrm{O}_{3}+\mathrm{TiO}_{2}\right)$, partially stabilized zirconia (PSZ), and super-Z alloys (20\% alumina and 80\% PSZ) [1-6]. Various types of TBCs are available. PSZ and Yttriastabilized zirconia (YSZ) are widely used and studied, and both contain zirconium oxide $\left(\mathrm{ZrO}_{2}\right)$. Apart from these two TBCs, $\alpha$-phase $\mathrm{Al}_{2} \mathrm{O}_{3}$ is a stable aluminum oxide that is often used as an addition to an existing TBC. By incorporating alumina in YSZ and PSZ, oxidation and corrosion resistances have been improved, as well as hardness and bond strength without causing any significant change in the elastic modulus or toughness. The four coatings types used in our study contain various proportional combinations of alumina, $\mathrm{ZrO}_{2}$, titanium oxide and PSZ. We used a $40 \mathrm{~kW}$ plasma spray system with a $7 \mathrm{MB}$ gun to spray ceramic oxides onto the surface of substrate of mild steel plates which had been initially grit-blasted, degreased and applied with a NiCrAl bond coat. We tested these specimens for wear and friction using standard laboratory equipment $[3,4]$.

\subsection{Wear loss and coefficient of friction tests}

We used the pin-on-disc wear testing machine to conduct dry-sliding wear tests and to measure the material weight loss $[7,8]$. This machine consists of a pin mounted on a stiff lever that serves as a frictionless force transducer, which is pressed against a rotating disc. Generally, using a plasma spray process, the pin surface is coated with a ceramic oxide, fixed to the arm and then pressed against disc with a known amount of force. We recorded the speed in revolutions per minute, the wear and frictional forces to determine the effect of the sliding speed, applied pressure, and wear loss of different types of coatings. We used a DUCOM pin-on-disc tribometer to carry out friction and wear tests on TBC specimens of $6 \mathrm{~mm}$ diameter. For the disc, we used an abrasive wheel coated with corresponding TBCs with a WA60K5V wheel specification. We performed sixteen tests on samples under 5, 15, 25 and $30 \mathrm{~N}$ normal loads. The test conditions included a track diameter of $80 \mathrm{~mm}$ and speed variations from 2.5 to $10 \mathrm{~m} / \mathrm{s}$ under atmospheric conditions. We varied the sliding distance from 2 to $8 \mathrm{~km}$. For the above conditions, we recorded the WL and COF values as per the standard test method ASTM G99. As the disc was rotated, we used a strain gauge sensor to measure the resulting frictional forces between the pin and the disc [8]. We then examined the ceramic TBCs to optimize the process parameters of the two tribological characteristic outputs $W L$ and COF. We measured the WL and COF of the ceramic coated surface with respect to four parameters levels with different type of coatings, and calculated the applied pressures between the coated pin and disc, the sliding distances, and the sliding velocities as shown in Table 3. 
Table 3 Experimental results and data preprocessing of tribological characteristics of TBC coatings.

\begin{tabular}{ccccccccc}
\hline \multirow{2}{*}{ Run No. } & \multicolumn{3}{c}{ TBC process parameters } & \multicolumn{2}{c}{ Experimental results } & \multicolumn{2}{c}{ Normalized data } \\
\cline { 2 - 9 } & $\begin{array}{c}\text { Applied } \\
\text { pressure } \\
(\mathrm{MPa})\end{array}$ & $\begin{array}{c}\text { Sliding } \\
\text { distance } \\
(\mathrm{km})\end{array}$ & $\begin{array}{c}\text { Sliding } \\
\text { velocity } \\
(\mathrm{m} / \mathrm{s})\end{array}$ & $\begin{array}{c}\text { Type of } \\
\text { coating }\end{array}$ & $\begin{array}{c}\text { Weight } \\
\text { loss/wear } \\
(\mathrm{mg})\end{array}$ & $\begin{array}{c}\text { Coefficient of } \\
\text { friction, } \mu\end{array}$ & $\begin{array}{c}\text { Weight } \\
\text { loss/wear } \\
(\mathrm{mg})\end{array}$ & $\begin{array}{c}\text { Coefficient of } \\
\text { friction, } \mu\end{array}$ \\
\hline Ideal sequence & & & & & & & 1 & 1 \\
1 & 0.05 & 2 & 2.5 & A & 0.17 & 0.075 & 1 & 0.576923 \\
2 & 0.05 & 4 & 5 & AT & 0.59 & 0.082 & 0.97882 & 0.523077 \\
3 & 0.05 & 6 & 7.5 & PSZ & 4.5 & 0.024 & 0.781644 & 0.969231 \\
4 & 0.05 & 8 & 10 & Super-Z & 5.8 & 0.02 & 0.716087 & 1 \\
5 & 0.15 & 2 & 5 & PSZ & 3.3 & 0.077 & 0.842158 & 0.561538 \\
6 & 0.15 & 4 & 2.5 & Super-Z & 9 & 0.062 & 0.554715 & 0.676923 \\
7 & 0.15 & 6 & 10 & A & 14 & 0.06 & 0.302572 & 0.692308 \\
8 & 0.15 & 8 & 7.5 & AT & 9.1 & 0.078 & 0.549672 & 0.553846 \\
9 & 0.25 & 2 & 7.5 & Super-Z & 9.7 & 0.065 & 0.519415 & 0.653846 \\
10 & 0.25 & 4 & 10 & PSZ & 20 & 0.07 & 0 & 0.615385 \\
11 & 0.25 & 6 & 2.5 & AT & 11 & 0.085 & 0.453858 & 0.5 \\
12 & 0.25 & 8 & 5 & A & 15 & 0.055 & 0.252143 & 0.730769 \\
13 & 0.3 & 2 & 10 & AT & 19 & 0.076 & 0.050429 & 0.569231 \\
14 & 0.3 & 4 & 7.5 & A & 13.3 & 0.05 & 0.337872 & 0.769231 \\
15 & 0.3 & 6 & 5 & Super-Z & 9 & 0.15 & 0.554715 & 0 \\
16 & 0.3 & 8 & 2.5 & PSZ & 9 & 0.061 & 0.554715 & 0.684615 \\
\hline
\end{tabular}

\section{Multi-response optimization of control factors}

We chose Taguchi's L16 orthogonal array experimental design consisting of 16 data sets to optimize the four process parameter levels used to determine the multiple tribological performance characteristics of coatings in severe working conditions. We conducted the experiments using the L16 layout of process parameters and normalized the WL and COF of tribological data, as shown in Table 3. Their target values are "the smaller-is-the better" criteria used in the grey analysis and evaluation of the optimal combination of process factors [11].

To normalize the experimental results, we preprocessed the data using Eq. (1), determined the sequence deviations using the same method with the help of Eq. (3), and used these sequence deviations to determine the distinguishing coefficients for Eq. (4). We determined the grey relational coefficients (GRCs) using Eq. (5) as shown in Table 4. We then averaged the GRCs using equal weighting to obtain the grey relational grade [12]. In this investigation, we used the orthogonal array of the Taguchi design method to calculate the mean grey relational grade for each parameter level, as shown in Table 5. Since the grey relational grade indicates the degree of correlation between the reference and comparability sequences, a larger GRA grade means that the comparability sequence exhibits a stronger relationship with the reference sequence [13]. We applied GRA to identify the most influential factor, based on a study finding that a combination of levels providing the largest mean response is the optimal factor combination for the lifespan of TBC in withstanding excessive wear conditions.

Table 5 shows grey relational grades and their order with respect to the multiple tribology characteristics of TBCs. The higher grade grey relations have better multi-objective characteristics. Hence, the grey relational grade order shows that experiment No. 3 has the optimal setting for multi objective performance with 
respect to WL and COF. We generated response tables using the Taguchi design method to calculate the mean grey relational grade for each tribological characteristic parameter level of TBCs along with the difference $\Delta$ and rank of each factor with respect to $\Delta$ as shown in Table 6.

Table 4 Deviation coefficients and grey relational coefficients of tribology characteristics of TBC coatings.

\begin{tabular}{|c|c|c|c|c|}
\hline \multirow{2}{*}{ Run No. } & \multicolumn{2}{|c|}{ Deviation coefficient } & \multicolumn{2}{|c|}{ Grey relational coefficient } \\
\hline & Wear loss & Friction & Wear loss & Friction \\
\hline Ideal sequence & & & 1 & 1 \\
\hline 1 & 0 & 0.423077 & 1 & 0.541667 \\
\hline 2 & 0.02118003 & 0.476923 & 0.959361 & 0.511811 \\
\hline 3 & 0.21835603 & 0.030769 & 0.696034 & 0.942029 \\
\hline 4 & 0.28391326 & 0 & 0.637826 & 1 \\
\hline 5 & 0.15784165 & 0.438462 & 0.760061 & 0.532787 \\
\hline 6 & 0.44528492 & 0.323077 & 0.528941 & 0.607477 \\
\hline 7 & 0.69742814 & 0.307692 & 0.417562 & 0.619048 \\
\hline 8 & 0.45032779 & 0.446154 & 0.526134 & 0.528455 \\
\hline 9 & 0.48058497 & 0.346154 & 0.5099 & 0.590909 \\
\hline 10 & 1 & 0.384615 & 0.333333 & 0.565217 \\
\hline 11 & 0.54614221 & 0.5 & 0.477946 & 0.5 \\
\hline 12 & 0.74785678 & 0.269231 & 0.400687 & 0.65 \\
\hline 13 & 0.94957136 & 0.430769 & 0.34493 & 0.53719 \\
\hline 14 & 0.66212809 & 0.230769 & 0.430245 & 0.684211 \\
\hline 15 & 0.44528492 & 1 & 0.528941 & 0.333333 \\
\hline 16 & 0.44528492 & 0.315385 & 0.528941 & 0.613208 \\
\hline
\end{tabular}

Table 5 Grey relational grades and their order.

\begin{tabular}{ccc||ccc}
\hline Run No. & Grey grade & Order & Run No. & Grey grade & Order \\
\hline 1 & 0.770833 & 3 & 9 & 0.550404 & 0.449275 \\
2 & 0.735586 & 4 & 10 & 0.488973 & 14 \\
3 & 0.819031 & 1 & 11 & 0.525344 & 13 \\
4 & 0.818913 & 2 & 13 & 0.44106 & 8 \\
5 & 0.646424 & 5 & 14 & 0.557228 & 16 \\
7 & 0.568209 & 7 & 15 & 0.431137 & 6 \\
\hline
\end{tabular}

Table 6 Response table for means of grey relational grade.

\begin{tabular}{ccccccc}
\hline \multirow{2}{*}{ Process parameters } & \multicolumn{3}{c}{ Grey relational grade } & \multicolumn{2}{c}{ Rank } \\
\cline { 2 - 5 } & Level 1 & Level 2 & Level 3 & Level 4 & \\
\hline Applied pressure $(\mathrm{MPa})$ & 0.7861 & 0.5651 & 0.5035 & 0.5001 & 0.2860 \\
Sliding distance $(\mathrm{km})$ & 0.6022 & 0.5776 & 0.5644 & 0.6107 & 0.0463 \\
Sliding velocity $(\mathrm{m} / \mathrm{s})$ & 0.5998 & 0.5846 & 0.6135 & 0.5569 & 0.0566 & 3 \\
Type of coating & 0.5929 & 0.5482 & 0.6215 & 0.5922 & 0.0732 \\
\hline
\end{tabular}

Total mean grey relational grade $=0.5877$ 
Table 6 shows that the greatest grey relational grade is obtained for the combination P1-D4-V3-C3, which represents the optimal combination of TBC control parameters with respect to the multiple tribological output characteristics that will increase the life of coated components. The P1-D4-V3-C3 combination comprises an applied pressure of $0.05 \mathrm{MPa}$, sliding distance of $8 \mathrm{~km}$, sliding velocity of $10.0 \mathrm{~m} / \mathrm{s}$ and a PSZ coating. Figure 2 shows plots of the main effect of the means of the grey relational grades, in which the dashed lines represent the total mean of the grey relational grade. Figure 3 shows the various residual plots of the grey relational grade to demonstrate the effectiveness of this technique when applied in an optimization study [13].

\section{Analysis of variance (ANOVA) for grey relational grade}

To investigate the significance level of control factors with respect to the multiple tribological characteristics of TBCs in severe working conditions, we used Minitab statistical software to perform an ANOVA to determine their GRA grades or ranks at a 95\% confidence level [14]. The Fisher's value, $F$, and the probability of significance, $P$, can be used to determine the significance of the tribological characteristic process parameters on the multiple performance characteristics. For a large value of $F$ or small value of $P$, the corresponding parameter has a significant effect on the performance characteristics, and we can estimate

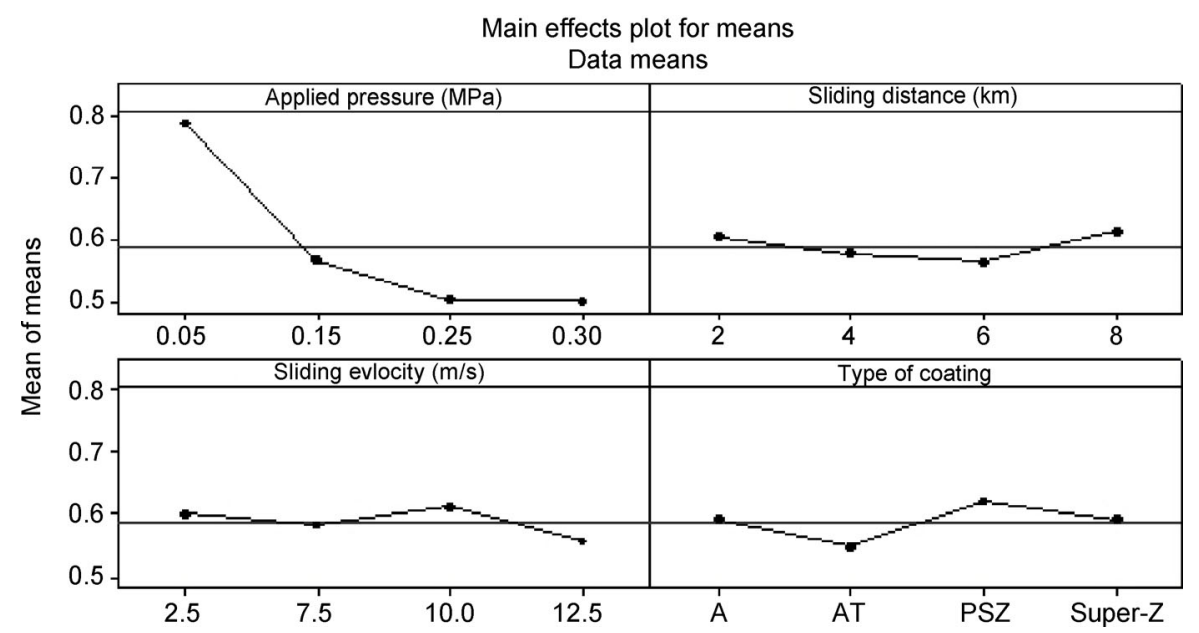

Fig. 2 Plot of total mean of grey relational grade vs. control factors.
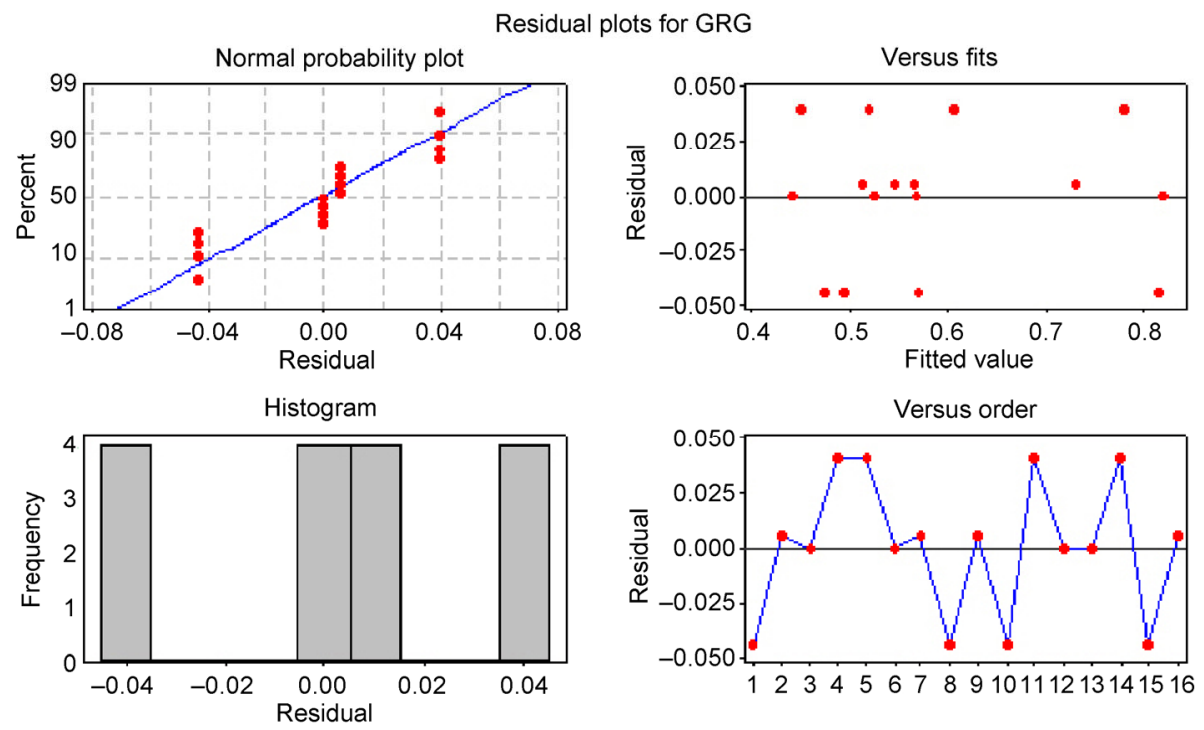

Fig. 3 Residual plots of grey relational grade using ANOVA. 
the percentage of the parameter's contribution. A residual plot for grey relational grade is shown in Fig. 3 [15].

Table 7 shows the ANOVA results for grey relational grade of the tested TBCs. We can see that applied pressure is the only significant tribological control factor that simultaneously considered WL and COF. The percentage of contribution of applied pressure control factor for the multi-response characteristics of TBCs is $85.33 \%$.

\section{Verification or confirmation test}

Using Taguchi based GRA, we obtained P1-D4-V3-C3 as the optimal combination of parameters to achieve minimum $\mathrm{WL}$ and COF. We then performed $\mathrm{a}$ verification test using P1-D4-V3-C3 setting to validate this analysis result. The confirmation test resulted in a WL of $4.5 \mathrm{mg}$ and a COF of 0.03 , which were better than the experimental results shown in Table 3. After identifying the optimal combination of tribological characteristics process factors for TBCs and the most influential factor, we verified the feasibility of the proposed combined Taguchi-based grey method by conducting further confirmation tests. Table 8 shows these confirmation test results [10]. We calculated the optimum grey relational grade, $\Gamma_{\mathrm{opt}}$, as follows:

$$
\Gamma_{\mathrm{opt}}=\Gamma_{\mathrm{m}}+\sum_{i=1}^{l}\left(\Gamma_{\mathrm{n}}-\Gamma_{\mathrm{m}}\right)
$$

where $\Gamma_{\mathrm{m}}$ is the total mean of the grey relational grade, $\Gamma_{\mathrm{n}}$ is the mean of the grey relational grade of the $i^{\text {th }}$ parameter at the optimal level, and $l$ is the number of most influential TBC parameters.

In both the cases, the WL and COF values for the optimal set of process parameters were sufficiently better than those of the initial process parameters. The improvement in the grey relational grade for this optimal parametric combination from that of the initial process parameters is 0.7556 . For our confirmation test, we performed three additional experiments using the optimal parameter settings and took the average of these three results. Table 8 shows the predicted grey relation grade values and verification test results, in which we see that the TBC characteristics with respect to WL decreased from 9.3 to $4.85 \mathrm{mg}$ and for the COF is reduced from 0.065 to 0.03 .

\section{Conclusion}

In this work, we used a Taguchi-based grey relational analysis to optimize the tribological characteristics of thermally sprayed TBCs with multiple performance characteristics. We simplified the multi-performance optimization by converting the multiple responses of

Table 7 ANOVA results for grey relational grade.

\begin{tabular}{ccccccc}
\hline Parameters & DF & SS & Adj MS & F & P & Contribution ratio (\%) \\
\hline Applied pressure $(\mathrm{MPa})$ & 3 & 0.218508 & 0.072836 & 15.59 & 0.025 & 85.33 \\
Sliding distance $(\mathrm{km})$ & 3 & 0.005520 & 0.001840 & 0.39 & 0.768 & 2.16 \\
Sliding velocity $(\mathrm{m} / \mathrm{s})$ & 3 & 0.007063 & 0.002354 & 0.5 & 0.706 & 2.75 \\
Type of coating & 3 & 0.010962 & 0.003654 & 0.78 & 0.578 & 5.28 \\
Error & 3 & 0.014015 & 0.004672 & & & 5.4732 \\
Total & 15 & 0.256067 & & & 100.00 \\
\hline
\end{tabular}

Table 8 Results of TBC tribological performance using the initial and optimal process parameters.

\begin{tabular}{|c|c|c|c|}
\hline & \multirow{2}{*}{ Initial process parameters } & \multicolumn{2}{|c|}{ Optimal process parameters } \\
\hline & & Prediction & Experiment \\
\hline Level & P2-D2-V2-C2 & P1-D4-V3-C3 & P1-D4-V3-C3 \\
\hline Wear loss & 9.3 & & 4.85 \\
\hline Coefficient of friction & 0.065 & & 0.03 \\
\hline Grey relational grade & 0.7556 & 0.8687 & 0.846 \\
\hline
\end{tabular}


the tribological characteristics into a single performance characteristic called the grey relational grade. We found that the tribological characteristics of the TBC can be simultaneously improved using the proposed method. From the experimental results, we found that applied pressure, type of coating, sliding velocity and sliding distance influence both the tribological measurements of WL and COF. These study results can help to establish an optimal set of parameters to realize desired tribological quality characteristics. Further, our results demonstrate the feasibility of the proposed multi-response optimization technique to increase TBC life under severe working conditions. From the response table, we see that the largest grey relational grade is achieved for an applied pressure of $0.05 \mathrm{MPa}$ between the disc and TBC coated pin. ANOVA results for the grey relational analysis grades showed that applied pressure is the only significant thermal characteristic control factor influencing the multi-output characteristics and its contribution is quite large at $85.33 \%$ as compared to the other control factors of commercially available industrial ceramic coatings in the aerospace industry. Our confirmation tests/experiments revealed a 0.8687 improvement in the grey relational grade by the optimal combination of parameters, compared to 0.8168 for the initial parameter setting.

The wear rate and coefficient of friction mainly depend on loading/pressure conditions. Initially, abrasion mainly occurs and then once the bond coat is exposed to the disc, material is lost by adhesion. Coated samples showed much less wear at room and high temperatures. At higher temperatures, above $375^{\circ} \mathrm{C}$, an oxide layer forms and there is a reduced coefficient of friction due to the formation of interface oxide layers. The superior wear resistance of coated samples at high temperature justifies using at high temperature applications involving sliding contact.

\section{Conflict of Interest}

The authors declare that they have no conflict of interest.

Open Access: The articles published in this journal are distributed under the terms of the Creative Commons Attribution 4.0 International License (http:// creativecommons.org/licenses/by/4.0/), which permits unrestricted use, distribution, and reproduction in any medium, provided you give appropriate credit to the original author(s) and the source, provide a link to the Creative Commons license, and indicate if changes were made.

\section{References}

[1] Fazlur R J, Yunus M. Benefits of TBC coatings on engine applications. In International Conference INCAM 2009 at Kalsalingam University, Tamil Nadu, India, 2009.

[2] Pan L K, Wang C C, Wei S L, Sher H F. Optimizing multiple quality characteristics via Taguchi method-based grey analysis. J Mater Process Technol 182: 107-116 (2007)

[3] Yunus M, Fazlur R J. Optimization of usage parameters of ceramic coatings in high temperature applications using Taguchi design. Int J Eng Sci Technol 3(8): 6364-6371 (2011)

[4] Yunus M, Fazlur R J, Feroz K S. Evaluation of machinability characteristics of industrial ceramic coatings using genetic programming based approach. Int J Eng Sci Technol 2(2): 126-137 (2011)

[5] Yunus M, Fazlur R J, Feroz K S A. Genetic programming approach for the prediction of thermal characteristics of ceramic coatings. Int J Ind Engg Resd Devel 2(1): 69-79 (2011)

[6] Yunus M, Fazlur R J. Some investigations on mechanical and tribological characteristics of industrial ceramic coatings. Int J Sci Res 1(4): 156-170

[7] American Society of Materials. Introduction to Thermal Spray Processing, Handbook of Thermal Spray Technology. ASM International, Cleveland, USA.

[8] Ramachandran K, Selvarajan V, Sree K K P. Microstructure, adhesion, microhardness, abrasive wear resistance and electrical conductivity of plasma sprayed alumina and alumina-titania coatings. J Thin Solid Films 315: 144-152 (1997)

[9] Deng J L. The introduction to grey system theory. J Grey System 1(1): 1-24 (1989).

[10] Roy N, Kuar A S, Mitra S, Acherjee B. Nd:YAG laser microdrilling of SiC-30BN nanocomposite: Experimental study and process optimization. In 5th International \& 26th All India Manufacturing Technology Design and Research Conference (AIMTDR 2014), IIT Guwahati, Assam, India, 2014: 224-226. 
[11] Sadasiva Rao T, Rajesh V, Venu Gopal A. Taguchi based grey relational analysis to optimize face milling process with multipl performance characteristics. In International Conference on Trends in Industrial and Mechanical Engineering (ICTIME'2012), Dubai, 2012: 166-170.

[12] Mishra P C, Das D K, Ukamanal M, Routara B C, Sahoo A. K. Multi-response optimization of process parameters using Taguchi method and grey relational analysis during turning AA 7075/SiC composite in dry and spray cooling environments. Int J Ind Eng Comput 6: 445-456 (2015)

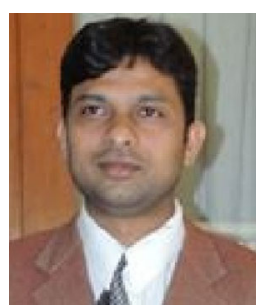

Mohammed YUNUS. He received the B.E. degree in mechanical engineering from Gulbarga University, India in 1997, received the M. Tech. degree in machine design from Visvesvaraiah Technological University, India in 2000, and received $\mathrm{PhD}$ degree in thermal and design engineering from Anna University, Chennai, India in 2012. He worked as Professor and PG Head in Thermal

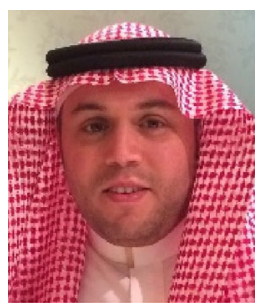

Mohammad S. ALSOUFI. He received the $\mathrm{BSc}$ degree in mechanical engineering from Umm Al-Qura University in 2004, and he received the MSc and $\mathrm{PhD}$ degrees in advanced mechanical engineering from Warwick University in the United Kingdom in 2007 and 2011, respectively. He worked as assistant professor in Mechanical
[13] Kannan, S, Kishawy H A. Surface characteristics of machined aluminum metal matrix composites. Int $J$ Machine Tools Manufact 46: 2017-2025 (2006)

[14] Krishna A A, Reddy S R, Reddy P R. Temperature prediction in orthogonal machining of $\mathrm{A} 1 / \mathrm{SiCp}$ composites. Int $J$ Emerg Technol Adv Eng 2(6): 223-229 (2012)

[15] Suryanarayanan K, Praveen R, Raghuraman S. Silicon carbide reinforced aluminum metal matrix composites for aerospace applications: A literature review. Int J Innov Res Sci Eng Technol 2(11): 6336-6344 (2013)

Engineering Department, HKBK College of Engineering, Bangalore, India for 2 years. Now, he is working as associate professor in Mechanical Engineering Department, College of Engineering and Islamic Architecture at Umm Al-Qura University for 2 years. He has published 65 technical papers in reputed international journals in different fields. His research areas are CFD, FEM, materials engineering, optimization, injection molding, TBC, surface characterization, and alternate fuels.

Engineering Department, Collage of Engineering and Islamic Architecture at Umm Al-Qura University for four years. Now, he is working as associate professor in Mechanical Engineering Department, Collage of Engineering and Islamic Architecture at Umm Al-Qura University. His research areas are nano-technology, nano-tribology, nano-science, surface characterization, and measurements. 